\title{
An effect of thermo-stimulation of lower abdomen on autonomic nervous system: An experimental study
}

\author{
Kyeong Han Kim , Jong Uk Kim , Bo Hyun Kim, Jin Hyeon Shin, Seong Jin Hong , \\ Sang Ryong Lee, Tae-han Yook*
}

Department of Preventive Medicine, College of Korean Medicine, Woosuk University Department of Acupuncture \& Moxibustion Medicine, College of Korean Medicine, Woosuk University

Department of Korean Medicine, College of Korean Medicine, Woosuk University

\section{Key Words}

thermo-stimulation, CV4, autonomic nervous system, HRV, EMG

\begin{abstract}
Objective: DIt is need to evaluate he changes of the bio-signals through the hot-cold stimulation in the CV4.

Methods: The 30 healthy participants were enrolled and randomly allocated, to one of three groups(10 participants for each group): the hot stone therapy(HST) group, or the cold stone therapy(CST) group or no treatment group(NT). All the participants took a rest for 10 minutes for stability before the test. And additional 10 minute rest after measurements of skin test and sEMG. After that two group received hot or cold stone therapy for 30 minutes and one group treated nothing with HRV test.
\end{abstract}

Results: HRV LF value showed a significant increase over time in all three groups, but there was no significant difference between groups but HRV HF value did not show any significant difference with time in all three groups and there was no significant difference between groups. sEMG value showed a significant increase in the left side of the masseter muscle of the HST group and sebum levels was a significant decreased in HST group

Received: Dec 21, 2017 Reviewed: Mar 20, 2018 Accepted: May 17, 2018

(c) This is an Open-Access article distributed under the terms of the Creative Common Attribution Non-Commercial License (http://creativecommons.org/licenses/by-nc/4.0/) which permits unrestricted noncommercial use, distribution, and reproduction in any medium, provided the original work is properly cited.

(@) This paper meets the requirements of KS X ISO 9706, ISO 9706-1994 and ANSI/NISO Z39.48-1992 (Permanence of Paper). but no significant meaning was found.

Conclusion: There was no objective evidence that hot-cold stimulation produced bio-signals changes in comparison to the control group, but additional studies are needed as the subjects were limited.

\section{Introduction}

The human body represents an appropriate physical response to an external stimulation in order to maintain homeostasis. This is indicated by an involuntary control system, which is commonly referred to as the autonomic nervous system (ANS).[1] The autonomic nervous system consists of sympathetic nervous system and parasympathetic nervous system, and performs a wide range of roles, including controlling the heart rate, blood pressure, digestive functions, secretion activities, uring, sweating, and body temperature. [1] When the body is faced with stress, the ANS changes the body through appropriate stimulation, typically causing increased heart rate, blood pressure, and anxiety and awakening.[2]

Heart Rate Variability (HRV) is an index that shows the functional status of the ANS through changes in the heart rate, and it bio-function signal of the cardiovascular system, along with trans-cranial doppler(TCD), pulse wave, and pulse rate. $[1,3]$ In particular, the power spectrum analysis of HRV separates the major vari- 
ation patterns by frequency. It will assess the overall function of the ANS, the state of balance between sympathetic nervous system and parasympathetic nervous system, and their activity. Because of this, HRV is widely used in health and patient populations as a tool for measuring cardiovascular responses among ANS.[3]

Surface Eletromyography (sEMG) is a method for measuring the electrical signal of a motor unit and it is non-invasive and quantitative using surface electrodes. [4] In this study, sEMG of masseter muscle, which is known as associated with emotional tension and sensitive to temperature stimulation. Masseter muscle belongs to foot yangmyung meridian-muscle, which is highly related to the surface and the deep-depth abdomen. Thus, it was assumed that tmasseter muscle would have an unusual reaction to the abdominal irritation.

In addition, hyperactivity of sympathetic nerves increases the activity of the sweat glands, which reduces electrical resistance of skin. This skin conductance response is particularly important in measuring the response of the ANS changes. Therefore, it is expected that the increased activity of sweat glands will cause changes in the skin's moisture and oil quality. While studies have been conducted on the response of the ANS to herbal acupuncture or acupuncture treaatments[5], comparative study on the effects of temperature stimulation on local areas on the ANS is insufficient. Therefore, this study was intended to quantitatively identify changes in the body through temperature stress tests in healthy subjects.

\section{Materials and Methods}

\section{Participants}

The 30 healthy participants were recruited from the Woosuk university of Korean medicine hospital specifically for the study. Inclusion criteria were (1) Male over 20 years old and under 30 years old in Korean age; (2) People who voluntary involve and write a consent; (3) People who could communicate well about the experiment. Exclusion criteria were (1) People who have history of injury of central nervous system; and (2) People who have history of cardiovascular, endocrine, or autonomic nervous system disease; (3) People who took a short-term activating drug or food which could lead autonomic nervous stimulation between one hour; (4) People who took a long-term activating drug or food which could lead autonomic nervous stimulation between 72 hours; (5) People who could not be in static condition; (6) People who have history of facial disease which could lead to aftereffects; (7) People who had had actions or exercise which could affect electrical characteristics of muscle; (8) People who took a drug which could affect electrical characteristics of muscle; and (9) People who were judged as inappropriate volunteers by the manager of clinical study.

Participants who gave written informed consent were enrolled and randomly allocated, to one of three groups(10 participants for each group): the hot stone therapy(HST) group, or the cold stone therapy(CST) group or no treatment group(NT). Ethical approval for this study was given by the ethics committee of Woosuk university of
Korean medicine hospital (IRB Approval No. WSOH IRB M1706-01-01).

\section{Design}

The study was a randomized, controlled clinical trial but not blinded. All the participants took a rest for 10 minutes for stability before the test. And additional 10 minute rest after measurements of skin test and sEMG. After that two group received hot or cold stone therapy for 30 minutes and one group treated nothing with HRV test.(figure 1).

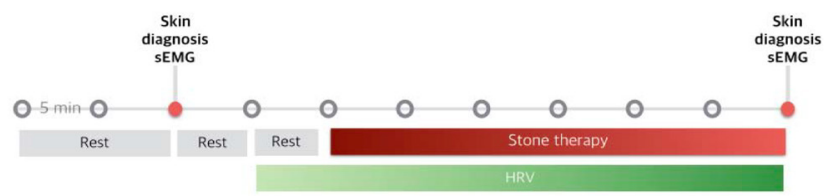

Figure 1 A timetable of the experiment

\section{Treatment}

The test site was kept isolated from external stimulation in order to minimize the stimulation of the ANS. The site was kept at an indoor temperature of $24^{\circ} \mathrm{C}$ to $26^{\circ} \mathrm{C}$ with an average humidity of $60 \%$. The windows were closed to block the noise, and the black curtains was closed and lights were turned off to block direct optical stimulation. However, indirect lighting was installed at $1 \mathrm{~m}$ away from the head side of bed to prevent falling asleep. The participant Participants had to look at the ceiling on the bed and lie naturally.

All treatments were conducted between 9AM and 12AM and $2 \mathrm{PM}$ and $5 \mathrm{PM}$ by trained clinical researcher under the guidance of the manager.

This study was a temperature-stimulating test, and the stone was a pure basalt product. $7.5 \mathrm{~cm}$ in diameter. To prevent burns caused by direct contact with the skin, refer to previous study[6,7], $43^{\circ} \mathrm{C}$ to $48^{\circ} \mathrm{C}$ was appropriate. The stone heated from $45^{\circ} \mathrm{C}$ to $50^{\circ} \mathrm{C}$ was located $\mathrm{CV} 4$ for HST group. The temperature of the cold stimulation had no standard for safety. Therefore, it was agreed upon by researchers on a temperature that did not exhibit negative physical responses, such as pain or discomfort. So same stone as HST group was used. Stone was cooled from $10^{\circ} \mathrm{C}$ to $15^{\circ} \mathrm{C}$ was located $\mathrm{CV} 4$ for CST group. Controls were placed in the same environment, in the same time period, without any temperature stimulation.

\section{Evaluation}

In this study, it was measured three kind of bio-signals. First, it was sEMG which is measured the electrical signal of a motor unit. In this study, both sides of masseter muscle were measured for the previously known[8-10] as stress showed changes in electromyogram and nerve conduction using QEMG- 4XL(Laxtha. Co.,) The sEMG was measured twice before and after treatment, and the root 
mean square(RMS) of left and right was recorded respectively after leading to masseter muscle contraction. The measured electrodes were HEX Dual Electodes Product \#272 S(Noraxon Co.,), and Electrode SEED T246H was used with ground electrode.

Second measurement is the HRV test. Heart rate is often used for stress tests because it can identify changes in the ANS. In this study, we used the Poly G-I (Laxtha Co.,), and the electrode Red Dot TM Monopolar Electrode 2237 (3M Co.,). For a total of 30 minutes, the participants' heart rate changes were continuously measured, and the changes over time were analyzed in a series of six segments at five-minute intervals. The measurement results were recorded through time-domain analysis and frequency- domain analysis and the statistical analysis of the variation in $\mathrm{LF}$ and $\mathrm{HF}$ values.

Third, changes in skin surface conditions were observed through skin diagnosis. SDM skin diagnosis system (Bomtech Co.,) used in this study is an automated skin measuring program system that uses UV camera for percutaneous moisture. In this study, we made

a statistical analysis of the patterns of changes between the front and back after measuring the left and right sides, moisture in the full part, and oil quality.

\section{Statistical analysis}

Software used for all analyses was SPSS 15.0 for Windows (IBM, Chicago, IL). Values are presented as mean \pm standard deviation (SD), and a p value $<0.05$ indicated statistical significance.

To determine homogeneity of three groups, a one way ANOVA was conducted. In addition, the repeated measured ANOVA was conducted to verify changes in HRV values over time and interactions between groups. In case of the covariance structure is not satisfied with the assumptions of sphericity in the result of repeated measured ANOVA, p-value was calculated based on Greenhouse-Geisser value. Also student t-test was used to evaluate the differences before and after the treatment.

Table 1 Basic Characteristics of Participants

\begin{tabular}{ccccc}
\hline Classification & $\begin{array}{c}\text { Age } \\
(\mathrm{N}=30)\end{array}$ & $\begin{array}{c}\text { Height } \\
(\mathrm{N}=30)\end{array}$ & $\begin{array}{c}\text { Weight } \\
(\mathrm{N}=30)\end{array}$ & $\begin{array}{c}\text { Body temperature } \\
(\mathrm{N}=30)\end{array}$ \\
\hline Mean $\pm \mathrm{SD}$ & $23.47 \pm 2.10$ & $175.52 \pm 4.90$ & $\underline{72.39 \pm 8.96}$ & $36.57 \pm 0.12$ \\
\hline
\end{tabular}

Table 2 Result of repeated measured ANONA in LF value

\begin{tabular}{|c|c|c|c|c|c|c|}
\hline \multicolumn{2}{|c|}{ Source } & Sum of & $\mathrm{df}$ & Mean & $\mathrm{F}$ & Sig. \\
\hline \multirow{2}{*}{$\begin{array}{l}\text { Between } \\
\text { Subject }\end{array}$} & Group & 10.594 & 2 & 5.297 & 2.904 & .072 \\
\hline & Error & 49.252 & 27 & 1.824 & - & - \\
\hline \multirow{3}{*}{$\begin{array}{l}\text { Within } \\
\text { Subject }\end{array}$} & Time & 9.567 & 3.518 & 2.719 & 10.615 & $<.001$ \\
\hline & Time $\times$ Group & 3.423 & 7.037 & 0.486 & 1.899 & .078 \\
\hline & Error & 34.335 & 94.993 & 0.256 & - & - \\
\hline
\end{tabular}

\section{Result}

\section{Characteristics of Participants}

The 30 healthy participants are all male. Their average of age is $23.47 \pm 2.10$, and average of height is $175.52 \pm 4.90$, average of weight is $72.39 \pm 8.96$, and average of body temperature is $36.57 \pm 0.12$.

To determine homogeneity of three groups, a one way ANOVA was conducted. As the result, $\mathrm{LF}$ value $(\mathrm{p}=0.104)$, HF value $(p=0.432)$, skin moisture $(p=0.515)$, skin se$\operatorname{bum}(\mathrm{p}=0.316)$, right side of skin elasticity $(\mathrm{p}=0.442)$, left side of skin elasticity $(\mathrm{p}=0.564)$, right side of masseter muscle's sEMG value $(\mathrm{p}=0.233)$, left side of masseter muscle's $s E M G$ value( $p=0.356)$, None of the value had significant difference between group, the three groups would be homogeneous.

\section{HRV}

\section{Change of LF value}

Within each group, the change over time was significant. However, there was no significant difference in time between the three groups.

\section{Change of HF value}

Within each group, the change over time was not significant. Also there was no significant difference in time between the three groups.

\section{sEMG and Skin test}

The differences in the sEMG and skin test values before and after treatment were analyzed for each group. The level of sebum was significantly decreased in HST group and left side of masseter muscle's sEMG value was significantly increased in HST group. In other cases, no significant difference appeared.
Table 3 Result of repeated measured ANONA in HF value

\begin{tabular}{|c|c|c|c|c|c|c|}
\hline \multicolumn{2}{|c|}{ Source } & Sum of & df & Mean & $\mathrm{F}$ & Sig. \\
\hline \multirow{2}{*}{$\begin{array}{l}\text { Between } \\
\text { Subject }\end{array}$} & Group & 3.210 & 2 & 1.605 & 0.432 & .654 \\
\hline & Error & 100.376 & 27 & 3.718 & - & - \\
\hline \multirow{3}{*}{$\begin{array}{l}\text { Within } \\
\text { Subject }\end{array}$} & Time & 0.198 & 2.769 & 0.071 & 0.326 & .791 \\
\hline & Time $\times$ Group & 1.556 & 5.537 & 0.281 & 1.282 & .278 \\
\hline & Error & 16.382 & 74.751 & 0.219 & - & - \\
\hline
\end{tabular}


Table 3 The change in HF values over time between group

\begin{tabular}{|c|c|c|c|c|c|}
\hline \multicolumn{3}{|c|}{ Classification } & \multirow{2}{*}{$\begin{array}{c}\text { Before } \\
(\text { Mean } \pm \text { SD) } \\
96.9 \pm 39.0\end{array}$} & \multirow{2}{*}{$\begin{array}{c}\text { After } \\
(\text { Mean } \pm \text { SD }) \\
139.1 \pm 60.4\end{array}$} & \multirow{2}{*}{$\begin{array}{c}\mathrm{p} \text {-value } \\
.057\end{array}$} \\
\hline \multirow{6}{*}{ sEMG } & masseter & Hot & & & \\
\hline & muscle & Cold & $150.0 \pm 66.9$ & $138.7 \pm 51.2$ & .311 \\
\hline & (right) & No Treatment & $132.1 \pm 90.6$ & $132.6 \pm 97.9$ & .965 \\
\hline & masseter & Hot & $116.9 \pm 60.1$ & $139.6 \pm 60.7$ & $.043^{*}$ \\
\hline & muscle & Cold & $154.2 \pm 66.2$ & $143.1 \pm 49.1$ & .242 \\
\hline & ( & No Treatment & $118.0 \pm 67.9$ & $111.3 \pm 65.8$ & .217 \\
\hline \multirow{12}{*}{ Skin Test } & & Hot & $59.8 \pm 6.1$ & $56.8 \pm 7.5$ & .304 \\
\hline & moisture & Cold & $56.5 \pm 6.0$ & $53.4 \pm 4.3$ & .165 \\
\hline & & No Treatment & $57.5 \pm 7.3$ & $55.4 \pm 7.2$ & .339 \\
\hline & & Hot & $3716.6 \pm 2074.1$ & $3612.6 \pm 1967.6$ & $<.001^{* *}$ \\
\hline & sebum & Cold & $2957.2 \pm 1240.9$ & $2673.4 \pm 1253.4$ & .217 \\
\hline & & No Treatment & $4101.6 \pm 1616.8$ & $4064.8 \pm 1028.9$ & .896 \\
\hline & & Hot & $62.0 \pm 2.3$ & $58.6 \pm 7.2$ & .825 \\
\hline & $\begin{array}{c}\text { elasticity } \\
\text { (right) }\end{array}$ & Cold & $59.0 \pm 8.9$ & $58.3 \pm 7.3$ & .655 \\
\hline & & No Treatment & $61.4 \pm 2.4$ & $59.6 \pm 5.3$ & .367 \\
\hline & & Hot & $61.3 \pm 2.3$ & $60.6 \pm 5.2$ & .005 \\
\hline & $\begin{array}{c}\text { elasticity } \\
\text { (left) }\end{array}$ & Cold & $59.9 \pm 7.2$ & $60.1 \pm 7.2$ & .870 \\
\hline & & No Treatment & $62.0 \pm 1.3$ & $62.2 \pm 1.0$ & .662 \\
\hline
\end{tabular}

* p-value calculated by student t-test

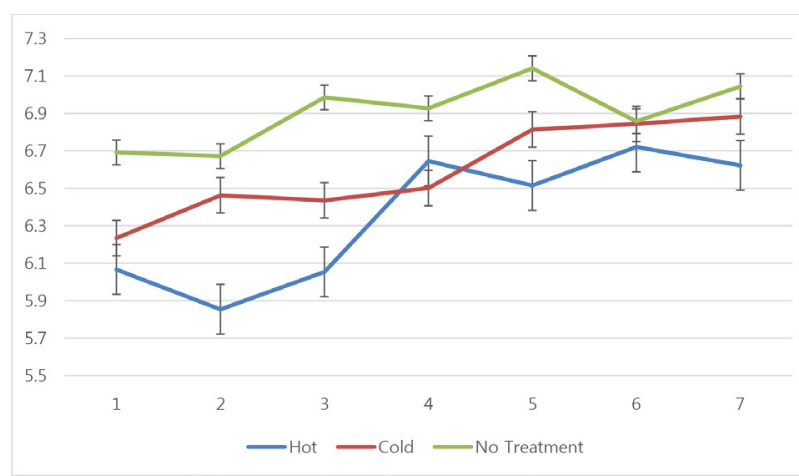

Figure 2 The change in LF values over time between group

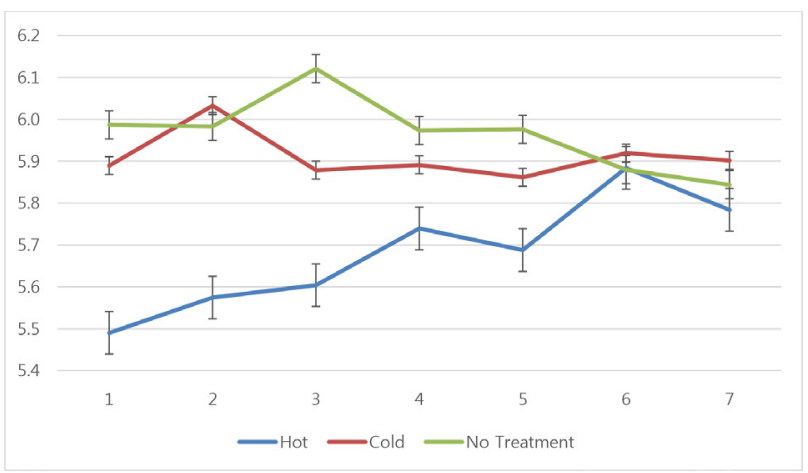

Figure 3 The change in HF values over time between group 


\section{Discussion}

A human is a homoiothermic animals that maintains the body temperature through contraction and relaxation of blood vessels when the temperature of the surrounding environment changes.[11] Normal cells, when the temperature of the skin tissue rises to about $40^{\circ} \mathrm{C}$, it is expan ded th at th e arteries and capillary vessels, promotin $g$ blood circulation, and contributing to pain experiences. [12] On the other hand, cold stimulation about $1^{\circ} \mathrm{C} 5 \mathrm{cau}$ ses con traction of blood vessels an d strain of mu scles, increasing hormone production that promotes cell growth. Through, hot-cold treatment has been widely used to relieve symptoms and prevent and treat diseases.[13]

In Korean medicine, also external temperature changes as an important factor affecting the heath and actively used hot-cold therapy. In particular, CV4 is the primary acupointI of conception vessel meridian, which frequently uses thermal therapy to adjust the function of the whole body.[14] Therefore, we conducted to objectively investigate the changes of the bio-signals through the hot-cold stimulation in the CV4.

A common study has shown that ANS is sensitive to changes in ambient temperature and that these changes could affect HRV.[15] The study also shows that the LF values have significantly increased both hot- cold stimulation over time. Considering that the LF values are related to the activity of the sympathetic nervous system, both hot-cold stimulation could be activating the sympathetic nerves of the human body. In addition, there was no significant change in the HF values associated with the activity of parasympathetic nerve. As LF values have not been significantly different from the controls, but it is similar result to the significant increase in LF values after moxibustion treatment.[16] As it is different from the belief that parasympathetic nerve commonly activated after thermal stimulation, Further research should be done to verify more accurately.

In sEMG and Skin test values, the level of sebum was significantly decreased in HST group and left side of masseter muscle's sEMG value was significantly increased in HST group. However, it is hard to say that it could have a meaning refer to overall changes.

This study has limitation. The number of subjects was limited to 10 in each group, the both practitioner and participants were not blinded. Also there was no precise control of the temperature of the stone. However, a randomized controlled study has been conducted and it could be pointed out that verify the effect of hot-cold stimulation of CV4 through the diagnostic device.

\section{Conclusion}

It was examined the change of HRV, sEMG, skin test value in HST, CST, NT group.

1. HRV LF Value showed a significant increase over time in all three groups, but there was no significant difference between groups.

2. HRV HF value did not show any significant difference with time in all three groups and there was no significant difference between groups.

3. The sEMG value showed a significant increase in the left side of the masseter muscle of the HST group, but no significant meaning was found.

4. Skin test results showed a significant decrease in sebum levels in the HST group, but no significant meaning was found.

There was no objective evidence that hot-cold stimulation produced bio-signals changes in comparison to the control group, but additional studies are needed as the subjects were limited.

\section{Conflicts of interest}

The authors have no conflicts of interest to declare.

\section{Acknowledgement}

This research was supported by Basic Science Research Program through the National Research Foundation of Korea(NRF) funded by the Ministry of Education. (No. 2015R1D1A3A01019492) 


\section{References}

1. Department of Biofuctional Medicine and Diagnosis of National Korean Medicine College. Biofunctional Medicine. Seoul(Korea) Koonja Press. 2008; 9-10.

2. Choi WS. Heart Rate Variadility and the Measurement of Stress. Korean J Stress Res. 2005; 13:59-63.

3. Lee JG, Koh SB, Chang SJ, Park JK, Yu JS, Lee JH. A Comparative Study of HRV between Normal and HwaByung: Subject to Kang-won Province Inhabitants in 2006. JON. 2008; 19:171-8.

4. Choi YM, Kim JU, Kim LH, Yook TH. A Study of the Electrical Properties of the Buccal Area using Facial Surface Electromyography. The Acupunct. 2017; 34: 75-82.

5. Kim YJ, Lee CH, Kim JU, Yook TH. Effects of Distilled Cervi Pantotrichum Cornu and Rehmannia glutinosa Pharmacopuncture at GB21. JAMS. 2005; 9:311-8.

6. Kwak H, Lee SY, Kim SB. Heat therapy and Cryotherapy in the Family Medicine

Field. J Korean Acad Fam Med. 2003; 24:877-83.

7. Moritz AR, Henriques .Studies of Thermal Injury. AmJ Pathol. 1947; 23(5):695-720.

8. Ruf S, Cecere F, Kupfer J, Pancherz H. Stress-induced changes in the functional

electromyographic activity of the masticatory muscles. Acta Odontol Scand. 1997;55: 44-8.

9. Yemm R. Variations in the electrical activity of the human masseter muscle occurring in association with emotional stress. Arch Oral Biol. 1969; 14:873-8.

10. Yemm R. A comparison of the electrical activity of masseter and temporal muscles of human subjects during experimental stress. Arch Oral Biol. 1971; 16:269-73.

11. Choi, J. H. and Park, J. H. The Effect of Feet Immersion in Hot and Cold Water on Hemodynamic and Thermoregulatory Responses. JKLES. 2009; 16:172-85.

12. Park, K. H., Kim, K. H. and Kim, J. H. Effect of the Ceragem Master Heat Bed for Posterior Neck Pain and Low Back Pain. JKOP. 2000; 14:133-40.

13. Sun, J., Zhang, A. and Xu, L. X. Evaluation of Alternate Cooling and Heating for Tumor Treatment. Int J Heat Mass Transf. 2008; 51:5478-85.

14. D.E. Youn. A Sutdy on the Moxa-extract Moxibustion Method. J Korean Acupunct Moxib Soc. 2006; 23:1-14.

15. Huang CM, Chang HC, Kao ST, Li TC, Wei CC, Chen C, Liao YT, Chen FJ. Radial pressure pulse and heart rate variability in heat- and cold-stressed humans. Evid Based Complement Alternat Med. 2011.

16. Shu Q, Sun D, Wang H, Lian F, Gerhard L, Daniela L, Intrid G, Chen L, He W, Wang Y. Differences of acupuncture and moxibustion on heart rate variability in qi- deficiency syndrome:a-randomized controlled trial. Zhongguo Zhen Jiu. 2017; 37(1):25-30. 